\title{
Effects of midazolam on acquisition and extinction of conditioned taste aversion
}

\section{memory in rats}

Shingo Ishitobi ${ }^{\mathrm{a}^{*}}$, Takao Ayuse ${ }^{\mathrm{b}}$, Harushi Yoshida ${ }^{\mathrm{a}}$, Kumiko Oi ${ }^{\mathrm{b}}$, Kazuo Toda ${ }^{\mathrm{c}}$, Takenori Miyamoto ${ }^{\mathrm{d}}$

${ }^{a}$ Department of Special Care Dentistry, Nagasaki University Hospital of Medicine and Dentistry, 1-7-1 Sakamoto, Nagasaki 852-8588, Japan

b Division of Clinical Physiology, Nagasaki University Graduate School of Biomedical Sciences, 1-7-1 Sakamoto, Nagasaki 852-8588, Japan

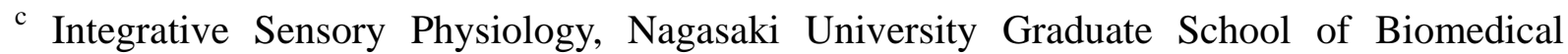
Sciences, 1-7-1 Sakamoto, Nagasaki 852-8588, Japan

d Laboratory of Behavioral Neuroscience, Department of Chemical and Biological Sciences, Faculty of Sciences, Japan Women's University, 2-8-1 Mejirodai , Bunkyo-ku, Tokyo 112-8681, Japan

Running head: Anesthetics effect on CTAM acquisition and extinction

${ }^{*}$ Corresponding author:

Shingo Ishitobi, Ph.D.

Department of Special Care Dentistry, Nagasaki University Hospital of Medicine and Dentistry, 1-7-1 Sakamoto, Nagasaki 852-8588, Japan

Tel: +81-95-849-7739 ; Fax: : +81-95-849-7752

E-mail: ishitobi@net.nagasaki-u.ac.jp 


\begin{abstract}
Some intravenous anesthetic agents such as midazolam are known to induce anterograde and retrograde amnesia. We analysed the effect of midazolam by the conditioned taste aversion (CTA) acquisition and retention. After the rats were offered $0.1 \%$ sodium saccharin (Sac) as conditioned stimulus (CS), an intraperitoneal (i.p.) injection of several concentrations (5 $30 \mathrm{mg} / \mathrm{kg}$ ) of midazolam was followed by an i.p. injection of $0.15 \mathrm{M} \mathrm{LiCl}$ (2\% of body weight) as unconditioned stimulus (US). The rats, which acquired CTA by every CS-US paradigm, strongly avoided Sac on the 1st test day after conditioning and maintained the avoidance for 3 days. We have already reported that Sac intake abruptly increased on the 2nd test day and the almost complete extinction occurred on the 3rd test day after conditioning by injection of subhypnotic dose of propofol before LiCl-injection. In contrast, we found that subhypnotic dose of midazolam suppressed not only CTA acquisition, but also CTA retention. On the other hand, an $\alpha$ 2-adrenergic blocker, yohimbin (1 mg/kg) suppressed only the CTA retention. These results suggest that the subhypnotic doses of midazolam firstly affect the acquisition mechanism of the CTA memory (CTAM ), resulting the suppression of the retention of CTAM.
\end{abstract}

Key words: midazolam ; CTA; memory; acquisition; extinction; amnesia, Yohimbin, noradrenergic system 
Intravenous anesthetics such as midazolam, one of benzodiazepine anesthetic agents, which possess both $\boldsymbol{\nabla}$-aminobutylic acid (GABA)-like [13, 29], are known to induce anterograde and retrograde amnesia in human [16,17] and rodents [24, 26]. In rodents, it has been reported that anterograde amnesia of an avoidance task was elicited by subhypnotic doses of the intravenous anesthetics, but retrograde amnesia was induced merely by hypnotic doses of these anesthetics [24, 25, 27].

Previous works using a CTA paradigm, where conditioned taste aversion memory (CTAM) related to malaise is formed when an animal consumes a novel taste such as saccharin (conditioned stimulus, CS) and then experiences the symptoms of poisoning such as LiCl (unconditioned stimulus, US) [9], show that the strong CTA is established rapidly by novel taste stimuli in a single learning procedure [5, 32]. The association between the CS and the US can proceed under deep anesthesia induced by pentobarbital or ketamine when hypnotic doses of these anesthetics are administrated after CS-presentation, or subhypnotic doses of them, which do not impair drinking, was applied before CS-presentation [6, 33].

However, subhypnotic doses of the intravenous anesthetics are often used for disabled patients even in light operation such as extraction of teeth to sedate their hyperactivity [22, 31]. We often encounter patients, who have lost the memory during operation after administration of sedative dose of these intravenous anesthetics while they preserved their consciousness during operation [22]. In the previous paper [15], we reported that subhypnotic but not hypnotic doses of propofol, one of non-benzodiazepine anesthetic agents, which has GABA-potentiating properties $[12,23,25]$ in mammalian central neurons, accelerate only the extinction of the long-term memory formed by the CTA. Recently, Yasoshima and Yamamoto (2005) has reported that conditioned animals did not rejected the CS transiently by a systemic 
injection of midazolam (1.5 mg/kg) before retention, although midazolam injection before CS did not affect acquisition and retention of CTA memory [34]. Their results shows that benzodiazepine such as midazolam applied before CS increases platability [34].

In the present study, we examined the effect of anesthetics applied between CS and US presentations on the long-term CTAM using several dosages of benzodiazepine agent, midazolam and compared the effects of midazolam with those of non-benzodiazepine, propofol. Furthermore, noradrenergic system has been reported to play an important role in the memory retention $[7,18,19]$. Therefore, we examined the effect of yohimbin , an $\alpha 2$ adrenoceptor antagonist on acquisition and retention of CTAM.

We purchased adult male Wistar rats, weighing 250-320 $\mathrm{g}$ at the beginning of experiment from an animal-supplying company. They were housed in individual wire mesh cages (285 $\mathrm{mm} \times 450 \mathrm{~mm} \times 210 \mathrm{~mm})$ in a temperature $\left(23^{\circ} \mathrm{C}\right)$-controlled room. They were allowed to ad-lib access to food (Dry pellets, MF, Oriental Yeast, Osaka) and tap water except for training and testing periods as described below. All rats were placed on a $20 \mathrm{hr}$ water-deprivation schedule and were allowed a $4 \mathrm{hr}$ access to distilled water (DW) for 5 days and amounts of DW intake for the first 20 min were measured. Means of the amount for last 3 were employed as control values (SDW) of preconditioning DW intake. The percent of saccharine consumption was calculated from the ratio of Sac-intake on each of test day 1, day 2 and day 3 (D1, D2, D3).

On Day 6, the animals were offered $0.1 \%$ sodium saccharin (Sac) as a CS for 20 min, and after $30 \mathrm{~min}$ interval, rats received an i.p. injection of $0.15 \mathrm{M} \mathrm{LiCl}$ (2\% of body weight) as an US. The animals were placed on the $20 \mathrm{hr}$ water-deprivation schedule again, and the amounts 
of Sac intake for 20 min were measured on the successive 3 days.

Nine groups of rats were trained according to the procedure described above. Each group of rats received i.p. injection of saline ( $0.9 \% \mathrm{NaCl}$ solution, Otsuka, Japan), several doses of anesthetics, midazolam (Dormicum, Roche, Basel) or yohimbin hydrochloride (Sigma, St. Louis, MO), after CS-exposure. The ten groups are as follows: Group 1: CS+US (Li(+)), Group 2: CS + saline + no US (Li(-)), Group 3: CS + saline + US (Li(+)), Group 4: CS + 5 mg/kg midazolam + Li(-), Group 5 9: CS + (0.5, 1, 5, 20 or $30 \mathrm{mg} / \mathrm{kg}$ midazolam) + US $(\mathrm{Li}(+))$ and Group 10: CS + $1 \mathrm{mg} / \mathrm{kg}$ yohimbin + US (Li(+)).

We calculated the following two categories of indices as the parameters for acquisition and retention of the long-term CTAM from volumes of pre- and postconditioning intake of DW and Sac [33]: Acquisition index (AI) = 1 - D1/ DW; Retention index (RI) $=1-(\mathrm{D} 2+$ D3)/2DW, where D1, D2 and D3 are total Sac intakes on the 1st, 2nd and 3rd test days, and DW is preconditioning mean DW intake. Results are expressed as mean \pm SE. The amount of Sac consumed on D1 and D2 was analyzed by a one-way analysis of variance (ANOVA). Sac consumption across the days of preconditioning (DW) and extinction (D1 D3) was analyzed with a two-way (group x day) ANOVA with repeated measures on days in each experiment. Post hoc analysis was performed using Bonferroni test. Comparison of two independent groups was analyzed using the two-tailed unpaired $t$-test. The significance level of all statistical analysis was set at $p<0.05$. All data analyses were conducted using StatView software (SAS Instruments. Inc.).

When Sac as a CS was paired with $\mathrm{LiCl}$ as a US, animals examined in this study readily acquired CTA as judged by comparing the amount of Sac intake on the 1st and 2nd test days with that of the preconditioning DW intake as shown in our previous paper [15]. However, the 
amount of Sac intakes gradually increased toward the 3rd test day (D3: $5.9 \pm 1.5 \mathrm{ml}$ ) as shown in previously reports $[3,5,6,10,15,33]$. When CS was paired with saline instead of $\mathrm{LiCl}$, CTA was never induced, and rather significant increase of Sac intake was observed on the 2nd to 3rd test day rather than decreaseas shown in our previous paper [15].

When rats received i.p. injection of a hypnotic dose of midazolam (30 mg/kg) or the same amount of saline, the properties of acquisition and extinction in CTAM unchanged (DW: 14.8 $\pm 0.7 \mathrm{ml}, \mathrm{D} 1: 0.8 \pm 0.4 \mathrm{ml}(p<0.0001), \mathrm{D} 2: 2.4 \pm 0.5 \mathrm{ml}(p<0.001)$ and D3: $6.0 \pm 1.4 \mathrm{ml}(p$ < 0.05), $\mathrm{n}=5$, for $30 \mathrm{mg} / \mathrm{kg}$ midazolam injection (Fig. 1A); DW: $13.2 \pm 1.1 \mathrm{ml}, \mathrm{D} 1: 1.8 \pm 0.2$ $\mathrm{ml}(p<0.001), \mathrm{D} 2: 4.2 \pm 1.0 \mathrm{ml}(p<0.01)$, D3: $8.4 \pm 0.9 \mathrm{ml}(p<0.05), \mathrm{n}=5$, for saline injection. These results are consistent with those of previous reports [6, 32].

On the other hand, when subhypnotic doses of midazolam were administrated after exposure to CS, the extinction was greatly accelerated and the amount of Sac intake greatly increased on the 2nd and 3rd test days. When i.p. injection of $5 \mathrm{mg} / \mathrm{kg}$ midazolam was followed by LiCl-injection, Sac intake greatly increased (DW: $10.5 \pm 0.7 \mathrm{ml}, \mathrm{D} 1: 2.8 \pm 0.9 \mathrm{ml}$ $(p<0.001), \mathrm{D} 2: 5.6 \pm 1.7 \mathrm{ml}(p=0.0213)$ and $\mathrm{D} 3: 9.7 \pm 1.5 \mathrm{ml}(p=0.6416), \mathrm{n}=5)($ Fig. $1 \mathrm{~B})$, when compared with the case of $30 \mathrm{mg} / \mathrm{kg}$ midazolam-injection (Fig. 1A).

Ratio of Sac-intake to SDW during 3 test days were shown in Figure $1 \mathrm{C}$ when $5 \mathrm{mg} / \mathrm{kg}$ midazolam was injected after CS-presentation. Sac intake in rats injected with $5 \mathrm{mg} / \mathrm{kg}$ midazolam was approximately 3 times larger than that in rats injected with saline instead of midazolam even on the 1st test day, and gradual augmentation of Sac intake occurred toward the 3rd test days rather than abrupt increase (Fig. 1C). The result is in contrast to the case of propofol, where the CTA learning was well acquired on the 1st test day, but the extinction abruptly appeared on the 2nd test day and finally Sac-intake reached more than $100 \%$ of 
preconditioning DW intake on the 3rd test day [15]. A two-way ANOVA with repeated measure for Fig.1C (group x day) detected significant main effects of three groups (saline, 5 $\mathrm{mg} / \mathrm{kg}$ and $30 \mathrm{mg} / \mathrm{kg}$ midazolam $)[F(2,12)=5.308, p=0.0223<0.05]$, but no significant difference in group $x$ day two-way interaction $[F(4,24)=0.631, p=0.6450]$. On the other hand, Bonfferoni test revealed that Sac-intakes are significantly different between $5 \mathrm{mg} / \mathrm{kg}$ and $30 \mathrm{mg} / \mathrm{kg}$ groups on each of D1, D2 and D3 (D1: $p=0.0076$; D2: $p=0.0266$; D3: $p=$ 0.0326), suggesting that subhypnotic dose of midazolam mainly affects the acquisition process of CTA so as to result in acceleration of extinction process of CTAM.

It has been known that after CS-exposure, illness-inducing drugs such as estradiol, which can induce CTA when it is used for US [35], accelerate the extinction of LiCl-induced CTA. No CTA was induced by an administration of $5 \mathrm{mg} / \mathrm{kg}$ midazolam, which was not followed by $\mathrm{LiCl}$ after exposure to Sac (DW: $14.6 \pm 2.1 \mathrm{ml}, \mathrm{D} 1: 13.3 \pm 2.7 \mathrm{ml}(p=0.2088)$, D2: $11.0 \pm 2.5$ $\mathrm{ml}(p=0.1795), \mathrm{D} 3: 16.7 \pm 4.1 \mathrm{ml}(p=0.4665), \mathrm{n}=3)$, indicating that the midazolam injection itself never induced any illness.

In the previous paper [15], we showed that propofol reduced the retention index (RI) of CTA in dose-dependent manner, whereas neither dose of propofol affected the acquisition index (AI). When the amount of anesthetics injected systemically was converted to molar concentration with an assumption that anesthetics can distribute uniformly into the extracellular space including blood plasma and intracellular fluid of the rat, which is $20 \%$ of body weight, in concentrations more than $10^{-4} \mathrm{M}$ for propofol, the lower concentrations of propofol are, the larger the suppression of retention (the acceleration of extinction) is. However, in less than $10^{-4} \mathrm{M}$ for propofol, the RI increased again, indicating that an optimal concentration exists for effects of propofol on the impairment of retention [15]. Presence of 
optimal concentration has been also reported in enhancing effect of propofol on $\mathrm{GABA}_{\mathrm{A}}$ receptors $[2,14]$. Midazolam also represented optimal concentration in acceleration effect on extinction of CTAM (Fig.2). However, tendency for midazolam to suppress the AI was observed, and post CS-injection of $613 \mu \mathrm{M}$ midazolam significantly suppressed the AI. Midazolam generated the optimal suppression of RI at higher concentration (75 $\mu \mathrm{M})$ than propofol (14 $\mu \mathrm{M})$ [15], while midazolam represented steeper dose-response relationship than propofol.

Recently, noradrenergic system has been reported to play an important role in the memory retention $[7,18,19]$. Therefore, we attempted to apply $1 \mathrm{mg} / \mathrm{kg}$ yohimbin, an $\alpha 2$ adrenoceptor antagonist, instead of anesthetics. When rats received i.p. injection of $1 \mathrm{mg} / \mathrm{kg}$ yohimbin, the properties of acquisition and extinction in CTA unchanged (DW: $12.4 \pm 0.8 \mathrm{ml}$, D1: $3.1 \pm 0.7 \mathrm{ml}(p<0.005), \mathrm{D} 2: 8.4 \pm 0.8 \mathrm{ml}(p<0.005)$ and D3: $12.5 \pm 0.7 \mathrm{ml}(p<0.005)$, $\mathrm{n}=10$ ). When $1 \mathrm{mg} / \mathrm{kg}$ yohimbin was systemically injected between CS and US, the extinction of CTAM was also remarkably accelerated without any evident effect on the acquisition. The result suggests that yohimbin reduced RI of CTAM without any effect on AI (Fig. 2B).

REM sleep has been reported to reinforce the memory consolidation. However, midazolam is known to induce NREM sleep rather than REM sleep [17]. Because $30 \mathrm{mg} / \mathrm{kg}$ of midazolam initiated the sleep-like situation, there was significant difference among acquisition index (AI) after saline- and $30 \mathrm{mg} / \mathrm{kg}$ midazolam-injection (Fig.2). Therefore, the sleep quality induced by high doses of midazolam may somewhat reinforce the acquisition process of CTA. However, effect of $5 \mathrm{mg} / \mathrm{kg}$ of midazolam on the CTA acquisition is not due to any sleep quality change because subhypnotic doses of anesthetics never induced any sleep 
at all.

Our previous study has shown that subhypnotic doses of an intravenous anesthetic agents, propofol accelerate the extinction of the long-term CTAM in a dose-dependent manner. In the present experiment, this effect was induced by both of non-benzodiazepine propofol and benzodiazepine midazolam. It has been reported that both of them activate $\mathrm{GABA}_{\mathrm{A}}$ receptor or enhance activation of $\mathrm{GABA}_{\mathrm{A}}$ receptor as GABA receptor agonist [2, 13, 14, 23, 24, 25]. Therefore, there is a possibility that $\mathrm{GABA}_{\mathrm{A}}$ receptors, which are modified by midazolam as well as propofol, are related to the memory retention of CTA. However, hypnotic dose of them did not affect the retention of CTAM. If the hypnotic effect of these anesthetics is due to the effect on $\mathrm{GABA}_{\mathrm{A}}$ receptors, subhypnotic doses of them must affect a different site from $\mathrm{GABA}_{\mathrm{A}}$ receptors.

There exist several reports that intravenous anesthetics such as midazolam affect various receptors including glycine [2], dopamine ( $\left.\mathrm{D}_{2}\right), N$-methyl-D-aspartate (NMDA) [28], and serotonin (5HT) receptors [1] or ion channels including voltage-gated $\mathrm{Ca}^{2+}, \mathrm{K}^{+}$or $\mathrm{Na}^{+}$channel $[8,10,11,14]$ other than $\mathrm{GABA}_{\mathrm{A}}$ receptors in the brain. On the other hand, formation of the long-term CTAM to novel tastant requires all of activations of NMDA receptors, muscarinic acetylcholine receptors, ß-adrenergic receptors (ß-AR), mitogen-activated protein kinase and protein synthesis [4], but extinction of CTAM only requires activation of ß-AR and protein synthesis [3]. Our present experiment revealed that an $\alpha$ 2-adrenergic receptor antagonist, yohimbin administrated between CS and US mimicked the enhancing effect of subhypnotic dose of propofol on the extinction of CTAM but not on the acquisition of CTAM, suggesting a possibility that $\alpha$ 2-adrenergic receptors are involved in the retention mechanism for CTAM.

Recently Yasoshima and Yamamoto (2005) has reported that a systemic injection of 
midazolam $(1.5 \mathrm{mg} / \mathrm{kg}$ ) before retention test transiently prevented conditioned animals from rejecting the CS, but midazolam injection before CS did not affect acquisition and retention of CTA memory, suggesting benzodiazepine agonist including midazolam transiently enhances the platability of CS [31]. In the present experiment, subhypnotic dose of midazolam affected the extinction after 1st retrieval, suggesting that the effect appears with long time delay, indicating that our experimental design and results for midazolam are essentially different from those reported by Yasoshima and Yamamoto (2005)[31].

Because subhypnotic dose of propofol did not significantly affect the acquisition rate of CTA, effect of propofol is possibly related to the retention process rather than to the formation process. Although whether the subhypnotic dose of propofol inhibits the retention process itself or accelerates the relearning process in the extinction remains undetermined at present, propofol possibly affect the molecular activation process during learning and memory.

In contrast to propofol, the present experiment demonstrated that midazolam tends to suppress the acquisition rate of CTA, and dose response relationship of midazolam is steeper than that of propofol. Furthermore, midazolam showed different mode of acceleration of extinction from propofol: midazolam gradually augmented Sac intake from the 1st test day to the 3rd test day, whereas propofol abruptly enhanced Sac intake on the 2nd and 3rd test days. Therefore, midazolam and propofol may produce similar effect on extinction of CTAM with differential mechanisms. Whether the suppression of CTA-retention is induced by the direct effect of midazolam or by the weak acquisition of CTA should be examined in the future experiment. The lesion of basolateral amygdala has been reported to induce an incomplete acquisition of CTA followed by the suppression of CTA-retention [30].

As shown in our previous paper, effect of propofol showed an inverted dose-dependency 
and the optimal concentration: The subhypnotic dose of these drugs accelerated the extinction of CTAM, but the hypnotic dose rather suppressed. The present experiment demonstrated that midazolam shows similar tendency regardless of the steepness of dose-dependency in midazolam effect. Thus, these facts suggest that midazolam and propofol may affect both mechanism contributing to acceleration and suppression of extinction in dose-dependent manner by different mechanisms.

Both benzodiazepine such as midazolam and non-benzodiazepine such as propofol are generally believed to initiate anesthesia through binding of anesthetics to $\mathrm{GABA}_{\mathrm{A}}$ receptor complex. Now we may be able to suppose that midazolam and propofol affect multiple receptor sites. Since the enhancing effect of anesthetics on $\mathrm{GABA}_{\mathrm{A}}$ receptors is dominant in higher dose, suppression of CTA retention does not appear evidently. In contrast, since effect on $\mathrm{GABA}_{\mathrm{A}}$ receptors diminishes and effect on other receptor site, which directly contributes to the memory consolidation, is dominant in lower doses, only suppression of CTA retention may be exposed. In this context, at subhypnotic doses, effect of benzodiazepine such as midazolam, on $\mathrm{GABA}_{\mathrm{A}}$ receptor site may be stronger than that of non-benzodiazepine such as propofol in rats, resulting in the steeper dose-response relationship with midazolam injection than that with propofol injection. These results roughly consistent with clinical observation that midazolam generally show a stronger amnesic effect than propofol [21,23, 29].

Furthermore, yohimbin , an $\alpha 2$ adrenoceptor antagonist, affect only on the retention of CTA in the similar manner propofol did, suggesting that $\alpha 2$ adrenoceptor, which is partially blocked by lower doses of propofol, contributes to the retention mechanism. The systemic application of yohimbin did not affect water and food intakes as well as CTA acquisition, indicating no peripheral effect of yohimbin. Whether midazolam does not have the same 
active site as that of yohimbin, but propofol does must be demonstrated after simultaneous application of midazolam and yohimbin or propofol. 


\section{Acknowledgements}

We thank Dr. Makoto Matsuo for their helpful comments on this manuscript. This work was supported in part by Grant-in-Aid for Scientific Research (11470441 to K.O. and 12671810 to T.M.) from the Ministry of Education, Science, Sports, Culture and Technology of Japan. 


\section{References}

[1] Barann M, Dilger JP, Bönisch H, Göthert M, Dybek A, Urban BW. Inhibition of 5-HT 3 receptors by propofol: equilibrium and kinetic measurements. Neuropharmacol 39 (2000) 1064-1074.

[2] Belelli D, Pistis M, Peters JA, Lambert JJ. The interaction of general anaesthetics and neurosteroids with GABA $A$ and glycine receptors. Neurochem Int 34 (1999) 447-452.

[3] Berman, DE, Dudai Y. Memory extinction, learning anew, and learning the new:

Dissociations in the molecular machinery of learning in cortex. Science 291 (2001) 2417-2419.

[4] Berman DE, Hazvi S, Neduva V, Dudai Y. The Role of identified neurotransmitter systems in the response of insular cortex to unfamiliar taste: Activation of ERK1-2 and formation of a memory trace. J Neurosci 20 (2000) 7017-7023.

[5] Bures J, Bermúdez-Rattoni F, Yamamoto T. Conditioned taste aversion: Memory of special kind. New York: Oxford Univ Press, 1998

[6] Buresová O, Bures J. The effect of anesthesia on acquisition and extinction of conditioned taste aversion. Behav Biol 20 (1977) 41-50

[7] Fresquet N, Angst MJ, Schleef C, Gobaille S, Sandner G. Adrenergic drugs modify the level of noradrenaline in the insular cortex and alter extinction of conditioned taste aversion in rats. Behav Brain Res 178 (2007) 39-46

[8] Friederich P, Urban BW. Interaction of intravenous anesthetics with human neuronal potassium currents in relation to clinical concentrations. Anesthesiol 91 (1999) 18531860

[9] García J, Kimeldorf DJ, Koelling RA. Conditioned taste aversion to saccharin resulting 
from exposure to gamma radiation. Science 122 (1955) 157-158

[10] Haeseler G, Störmer M, Mohammadi B, Bufler J, Dengler R, Hecker H, Piepenbrock S, Leuwer M. Propofol blocks human skeletal muscle sodium channels in a voltage-dependent manner. Anesth Analg 92 (2001) 1192-1198

[11] Haeseler G, Störmer M, Mohammadi B, Bufler J, Dengler R, Piepenbrock S, Leuwer M. The anesthetic propofol modulates gating in paramyotonia congenitia mutant muscle sodium channels. Muscle Nerve 24 (2001) 736-743

[12] Hales TG, Lambert JJ. The actions by propofol on inhibitory amino acid receptors of bovine adrenomedullary chromaffin cells and rodent central neurones. Br J Pharmacol 104 (1991) 619-628

[13] Hara M, Kai Y, Ikemoto Y. Enhancement of propofol of the g-aminobutylic acid response in dissociated hippocampal pyramidal neurons of the rat. Anesthesiol 81 (1994) 988-994

[14] Inoue Y, Shibuya I, Kabashima N, Noguchi J, Harayama N, Ueta Y, Sata T, Shigematsu A, Yamashita H. The mechanism of inhibitory actions of propofol on rat supraoptic neurons. Anesthesiol 91 (1999) 167-178

[15] Ishitobi S, Miyamoto T, Oi K, Toda K. Subhypnotic doses of propofol accelerate extinction of conditioned taste aversion Behav Brain Res 141 (2003) 223-228

[16] Jones C, Griffiths RD, Humphris G. Disturbed memory and amnesia related to intensive care. Memory 8 (2000) 79-94

[17] Kain ZN, Hofstadter MB, Mayers LC, Krivutza DM, Alexander G, Wang S-M, Reznick JS. Midazolam. Effects on amnesia and anxiety in children. Anesthesiol 93 (2000) 676-684 
[18] Korz V, Frey JU. Hormonal and monoamine signaling during reinforcement of hippocampal long-term potentiation and memory retrieval. Learn Mem. 14 (2007) 160-166

[19] Liu W, Yuen EY, Allen PB, Feng J, Greengard P, Yan Z. Adrenergic modulation of NMDA receptors in prefrontal cortex is differentially regulated by RGS proteins and spinophilin. Proc Natl Acad Sci U S A. 103 (2006) 18338-18343

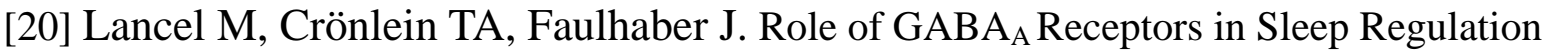
Differetial Effects of Muscimol and Midazolam on Sleep in Rats . Neuropsychopharmacol 15 (1996) 63-74

[21] Matsuki T, Ichinohe T, Kaneko Y. Amenisia for electric dental pulp stimulation and picture recall test under different levels of propofol or midazolam sedation. Acta Anaesthesiol Scand 51 (2007) 16-21

[22] Miner JR, Bachman A, Kosman L, Teng B, Heegaard W, Biros MH. Assessment of the onset and persistence of amnesia during procedural sedation with propofol. Acad Emerg Med 12 (2005) 491-496

[23] Nistri A, Berti C. Potentiating action of midazolam on GABA-mediated responses and its antagonism by Ro 14-7437 in the frog spinal cord. Neurosci Lett 39 (1983) 199-204

[24] O’Gorman DA, O’Connell AW, Murphey KJ, Moriaty DC, Shiotani T, Regan CM. Nefiracetam prevents propofol-induced anterograde and retrograde amnesia in the rodent without compromising quality of anesthesia. Anesthesiol 89 (1998) 699-706

[25] O’Shea SM, Wong LC, Harrison NL. Propofol increases agonist efficacy at the GABA . Brain Res 852 (2000) 344-348

[26] Quevedo J, de-Paris F, Vianna MR, Barichello T, Roesler R, Kapczinski F. Interaction 
between midazolam-induced anterograde amnesia and memory enhancement by treatments given immediately after training on an inhibitory avoidance task in rats. Behav Pharmacol 13 (2002) 319-322

[27] Salinas JA, Dickinson-Anson H, McGaugh JL. Midazolam administered to rats induces anterograde amnesia for changes in reward magnitude. Behav Neurosci 108 (1994) 1059-1064

[28] Schulte D, Callado LF, Davidson C, Phillips PEM, Roewer N, Sculte am Esch J, Stamford JA. Propofol decreases stimulated dopamine release in the rat nucleus accumbens by a mechanism independent of dopamine $\mathrm{D}_{2}, \mathrm{GABA}_{\mathrm{A}}$ and NMDA receptors. Br J Anaesth 84 (2000) 250-253

[29] Semba K, Adachi N, Arai T. Facilitation of serotonergic activity and amnesia in rats caused by intravenous anesthetics. Anesthesiol 102 (2005) 616-623

[30] Sigel E, Buhr A The benzodiazepine binding site of GABA receptors. Trends Pharmacol Sci 18 (1997) 425-429

[31] Wilson KE, Girdler NM, Welbury RR. A comparison of oral midazolam and nitrous oxide sedation for dental extractions in children. Anaesthesia. 61 (2006) 1138-1144

[32] Yamamoto T, Neural mechanisms of taste aversion learning. Neurosci Res 16 (1993) 181-185

[33] Yamamoto T, Fujimoto Y, Shimura T, Sakai N. Conditioned taste aversion in rats with excitotoxic brain lesions. Neurosci Res 22 (1995) 31-49

[34] Yasoshima Y, Yamamoto T. Effects of midazolam on the expression of conditioned taste aversion in rats. Brain Res 1043 (2005) 115-123

[35] Yuan DL, Chambers KC. Estradiol accelerates extinction of lithium chloride-induced conditioned taste aversions through its illness-associated properties. Hormone Behav 36 
(1999) 287-298 


\section{Figure legends:}

Fig. 1 Dose-dependent effect of midazolam on acquisition and retention of CTAM. A. Hypnotic dose of midazolam (30 mg/kg) . B. subhypnotic dose of midazolam (5 mg/kg) Midazolam was administrated between CS- and US-exposures. Open column shows preconditioning deionized water (DW) intake and hatched columns show saccharin intake on the 1st, 2nd and 3rd test days (D1, D2 and D3 respectively) in this and other figures. C. Ratio of saccharin intake after CTA acquisition with administrations of hypnotic and subhypnotic doses of midazolam. Ratio is expressed as percentages of preconditioning DW intake on D1, D2 and D3. The data are represented as mean \pm SEM in this and other figures. ${ }^{*}: p<0.05 ;{ }^{* *}: p<0.01 ;{ }^{* * *}: p$ $<0.001$.

Fig. 2 Effects of midazolam and yohimbin on acquisition index (AI) and retention index (RI). ). A. Dose-dependent effect of midazolam on AI and RI. B. Effect of $1 \mathrm{mg} / \mathrm{kg}$ yohimbin on AI and RI. Midazolam suppressed both AI and RI with steep dose-dependence. B. Effect of $1 \mathrm{mg} / \mathrm{kg}$ yohimbin on AI and RI. Yohimbin significantly suppressed only RI but not AI. *: $p<0.05$; **: $p<0.01$. 


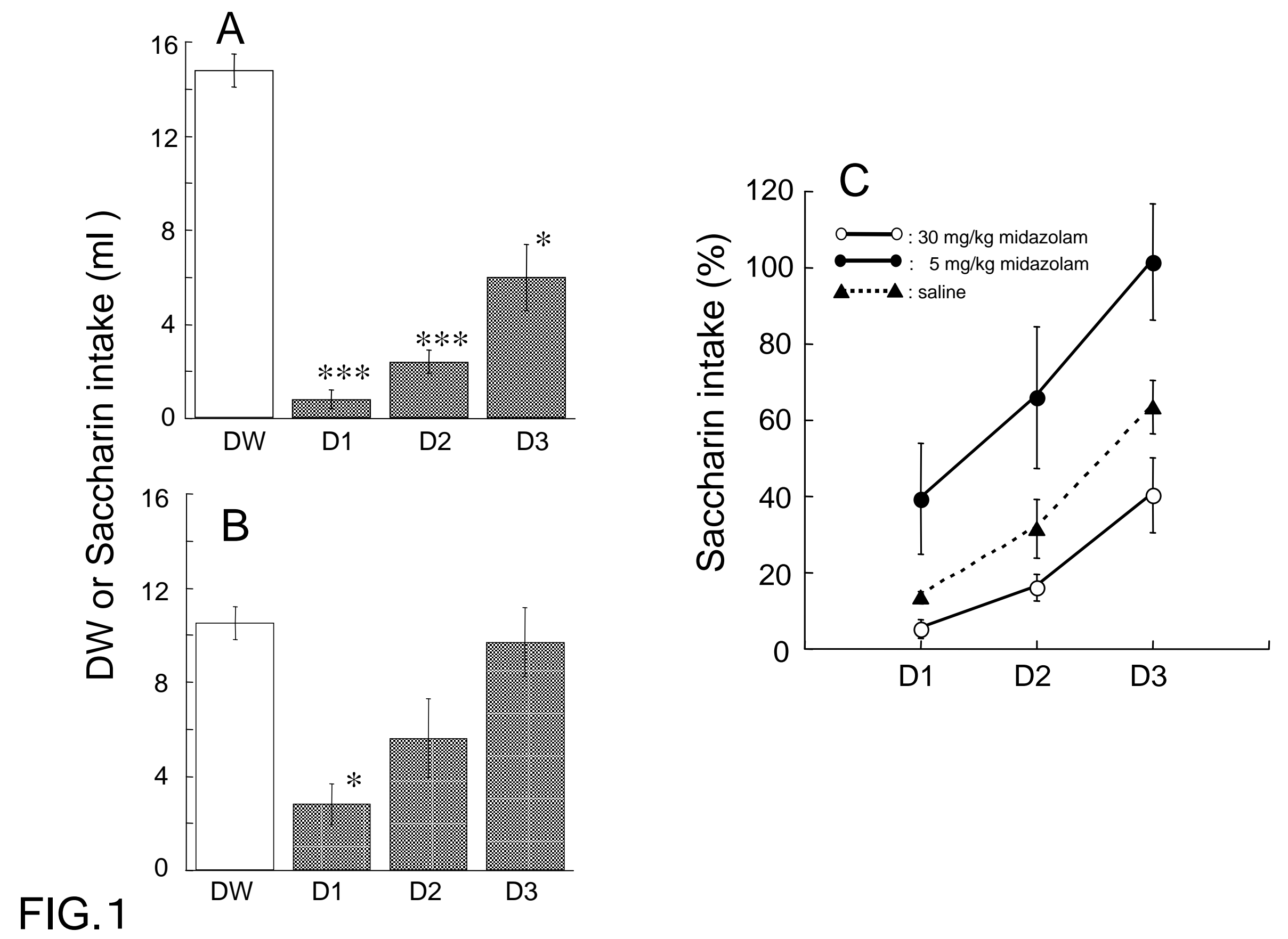



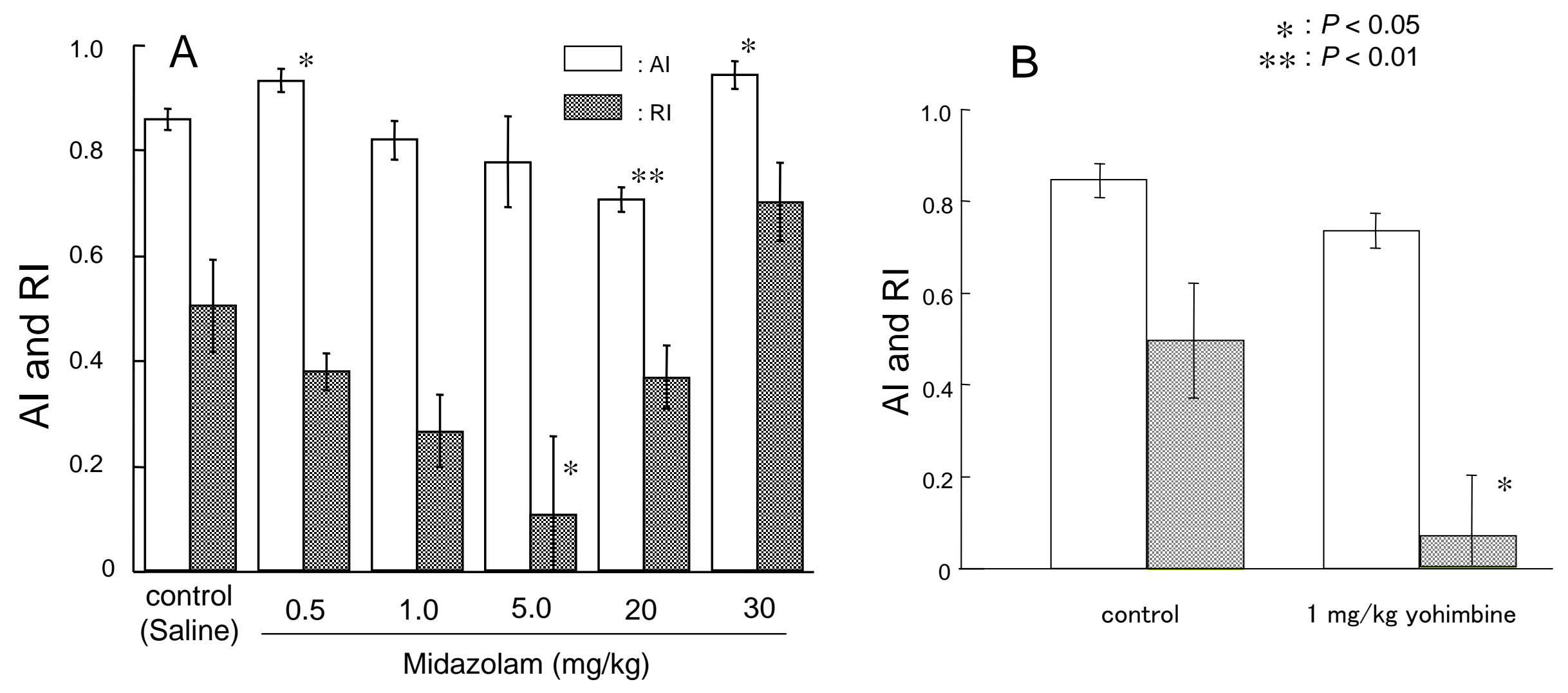

FIG.2 